\title{
Coulisses
}

Revue de théâtre

2| Automne 1990

Spécial Festival des idées : Besançon ville ouverte aux jeunes

\section{Le théâtre de poche. Essai, expérimentation}

Interview de Didier Femenias, responsable du Théâtre de Poche

Didier Femenias et Rédaction

\section{(2) OpenEdition}

Journals

Édition électronique

URL : http://journals.openedition.org/coulisses/1596

DOI : $10.4000 /$ coulisses. 1596

ISSN : 2546-9460

Éditeur

Presses universitaires de Franche-Comté

Édition imprimée

Date de publication : 1 novembre 1990

Pagination : $\mathrm{np}$

ISSN : 1150-594X

Référence électronique

Didier Femenias et Rédaction, « Le théâtre de poche. Essai, expérimentation », Coulisses [En ligne], 2 | Automne 1990, mis en ligne le 04 juillet 2017, consulté le 22 octobre 2019. URL : http://

journals.openedition.org/coulisses/1596; DOI : 10.4000/coulisses.1596

Ce document a été généré automatiquement le 22 octobre 2019.

Coulisses 


\section{Le théâtre de poche. Essai, expérimentation}

Interview de Didier Femenias, responsable du Théâtre de Poche

Didier Femenias et Rédaction

\section{Le Théâtre de Poche : une association} d'une certaine façon, Jean-Claude s'occupe de la gestion, et de la comptabilité. Il est trésorier de l'Association qui gère le Théâtre de Poche, dont je suis le secrétaire.

\section{L'orientation du Théâtre de Poche}

D. F. : C'est d'abord un lieu de création, mais des spectacles qui ont été créés ailleurs, peuvent aussi être présentés ici. Le Théâtre de Poche, par son nom même définit la dimension du lieu, la salle contient quarante spectateurs; cela privilégie un rapport intimiste entre les comédiens et les spectateurs, il y a une relation directe qui exige un jeu délicat. Ce lieu restreint, est un lieu d'expérimentation, pour des créateurs plus ou moins expérimentés.

Q.: On retrouve des professionnels et des amateurs?

D. F. : Il y a davantage de professionnels.

L. : Vous avez accueilli le Théâtre Universitaire cependant.

D. F. : Oui, dans le cadre de BVOJ, c'est dans un sens plus large de la jeune création dans les Arts vivants. On accueille aussi des cafés-théâtres, One-man shows, avec pour objectif de représenter des spectacles courts variant de dix à vingt minutes chacun. 


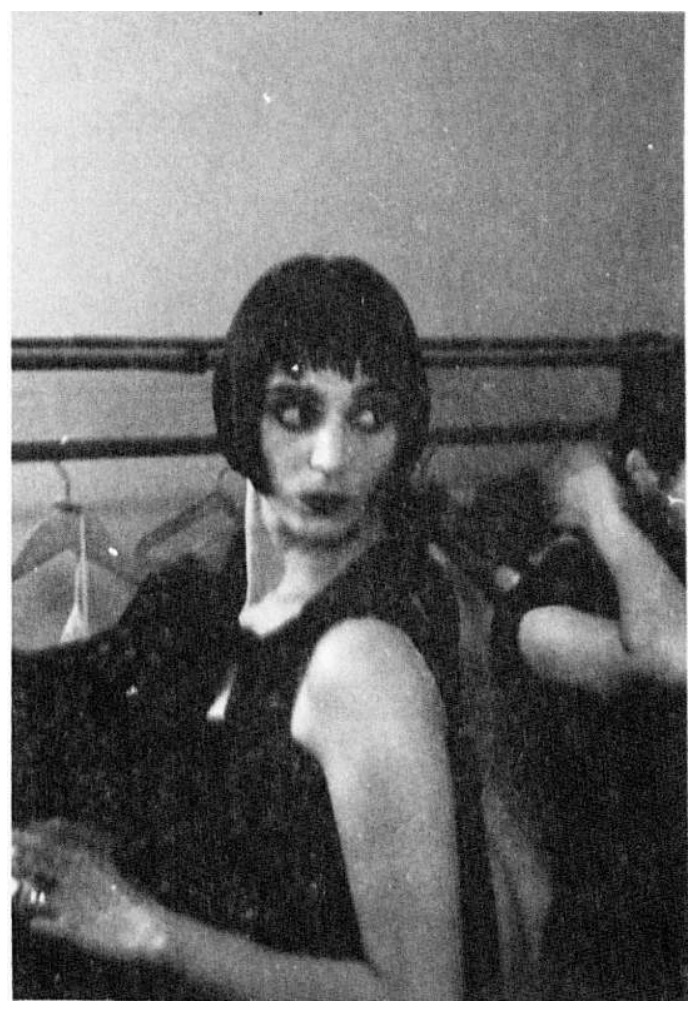

(c) Collectif Photo BVOJ 90.

\section{Le Théâtre de Poche et BVOJ}

D. F. : C'est la première fois que l'on présente des spectacles pour BVOJ en tant que lieu d'accueil et non pas de création.

Q. : Avez-vous opéré une sélection?

$101 /$ Il y a eu beaucoup de monde qui s'est dit : pourquoi ne pas participer à BVOJ ?

11 2/ Un mouvement de tassement vers la période de Pâques, les demandeurs oublient.

12 3/ Un mois et demi avant BVOJ, on a établi alors un calendrier. La sélection s'est faite d'elle-même.

\section{Les créations du Théâtre de Poche}

Q. : Quelle est votre méthode de travail lors de vos créations?

D. F. : J'aime le côté pluridisciplinaire. Ne pas être seulement comédien et faire appel aux autres formes d'art. Par exemple, dans Catilina, on a fait appel au Théâtre des Manches à Balais pour les marionnettes et j'ai demandé à un musicien de composer la bande-son. J'aime les côtés « carrefour » et synthèse.

\section{Les projets du Théâtre de Poche}

D.F. : D'abord, continuer et monter une marche. On a souffert au Théâtre de Poche de ces respirations qui se sont faites depuis 3, 4 ans : lancement puis essoufflement, puis à 
nouveau lancement... Il faut trouver un équilibre et constituer une équipe, plus ou moins importante, qui tourne. On est appelé à travailler ailleurs, il y a une rupture. Il faudrait que le Théâtre de Poche résolve les problèmes matériels et acquière son dynamisme propre : continuer avec le Théâtre mais aussi accueillir des musiciens, des chanteurs car il y a une bonne acoustique dans la salle et c'est une expérience d'affronter directement le public.

16 En résumé, que le Théâtre de Poche devienne un lieu où s'essaient tous « les nouveaux » $\mathrm{du}$ « spectacle vivant $»$. 